\title{
1 Quantitative genetic analysis of Cry1Ab tolerance in Ostrinia nubilalis
}

\section{Spanish populations}

3 Cristina M. Crava a , Gema P. Farinós ${ }^{\text {b }}$, Yolanda Bel a, Pedro Castañera ${ }^{\text {b }}$, Baltasar

4 Escriche $^{\text {a }}$

5 a Department of Genetics, University of Valencia, Dr. Moliner 50, 46100 Burjassot

6 (Valencia), Spain;

7 b Department of Environmental Biology, Centro de Investigaciones Biológicas,

8 CSIC, Ramiro de Maeztu 9, 28040 Madrid, Spain

9

10

11 Corresponding author: Baltasar Escriche, Department of Genetics, University of

12 Valencia, Dr. Moliner 50, 46100 Burjassot (Valencia), Spain. Phone: +34 9635 43401,

13 Fax: +34 9635 43029, email: baltasar.escriche@uv.es

14

15

16

17

18

19

20

21

22

23 


\section{Abstract} Tolerance to Bacillus thuringiensis Cry1Ab toxin in Spanish Ostrinia nubilalis

4 populations was analyzed by quantitative genetic techniques, using isolines established

5 from field-derived insects. $F_{1}$ offspring was tested for susceptibility to trypsin activated

6 Cry1Ab using a concentration that caused a mean larval mortality of $87 \%$ ( $\pm 17 \%$ SD).

7 The progeny of the most tolerant isolines (that had shown mortalities lower than 60\%)

8 was crossed to obtain the $F_{2}$ generation that was exposed to the same Cry1Ab

9 concentration. A clear reduction in mortality (62\% $\pm 17 \%$ SD) was observed. The upper

10 limit for heritability was estimated to range between 0.82 and 0.90 , suggesting that a

11 high part of phenotypic variation in tolerance to Cry1Ab was attributable to genetic

12 differences. An estimate of the minimum number of segregating factors indicated that

13 the loci involved in tolerance to Cry1Ab were at least two. The role of the cadherin 14 gene, which is a $B$. thuringiensis resistance gene in Lepidoptera, was assessed in the 15 most tolerant isolines by using an EPIC-PCR marker specifically developed for this 16 study. Association between cadherin and tolerance was obtained in one tolerant isoline; 17 however it could be not confirmed by segregation analysis in the $F_{2}$ progeny because $F_{2}$ 18 offspring was not viable. Our results indicate that the tolerance trait is common in 19 Spanish field populations. Quantitative genetic techniques may be helpful for estimating 20 the influence of genetic factors to Cry1Ab tolerance in O. nubilalis. 


\section{$1 \quad 1$ INTRODUCTION}

There is a wide consensus that the European corn borer, Ostrinia nubilalis

3 Hübner (Lepidoptera: Crambidae), is one of the most devastating pests of maize in

4 temperate climate regions. Larvae of this species tunnel through the stem of the plant

5 and feed within the stalk until pupation, causing yield losses. Since 1996, O. nubilalis

6 has been efficiently controlled by transgenic maize expressing the insecticidal Cry1Ab

7 protein from Bacillus thuringiensis (Berliner) (Bt). The worldwide adoption of Bt maize

8 is continually increasing, leaded by the US where plantings of Bt maize reached the

$967 \%$ of the total maize acreage in 2012 (NASS, 2012). In the European Union (EU), the

cultivation of Bt maize expressing Cry1Ab started in 1998 and to date it is the only Bt

11 crop allowed for cultivation. A few EU countries have occasionally grown Bt maize for

12 commercial purposes, but only in Spain the Bt cultivated surface has been steadily

13 rising since its introduction. In 2012, Spanish Bt maize area covered around 116,000

14 hectares (Ministerio de Agricultura, Alimentación y Medio Ambiente, 2012) and represented the $30 \%$ of the total maize-cultivated surface. This percentage substantially increases when some Spanish regions with higher adoption rates (such as the northeast corner) are considered (Farinós et al., 2011).

The continuous growing of Bt maize exercises a high selection pressure on the target pests. It might drive to the arising of the resistance trait in $O$. nubilalis field populations, particularly in those areas where the cultivation of $\mathrm{Bt}$ maize has been effectively implemented. In fact, field-evolved resistance of certain lepidopteran pests to Cry toxins have been reported after massive cultivation of Bt crops (Dhurua and Gujar, 2011; Kruger et al., 2011; Storer et al., 2010). Laboratory selection experiments have

24 shown that increased levels of resistance to Cry1Ab could be achieved in O. nubilalis 
1 2006; Farinós et al., 2004). Furthermore, differences in susceptibility to Cry1Ab

2 protein, attributable to natural variation in sensitivity to the toxin, have been reported

3 for O. nubilalis field populations (Saeglitz et al., 2006; Farinós et al., 2004; Siegfried et

4 al., 2001; Marçon et al., 1999). However, in spite of the intense selection pressure

5 exerted by the Bt maize and the potential to evolve resistance displayed by laboratory

6 experiments, resistance monitoring plans carried out in North America and Spain did

7 not detect a decrease in susceptibility of $O$. nubilalis larvae to Cry1Ab after the

8 introduction of Bt maize (Siegfried and Hellmich, 2012; Farinós et al., 2004).

In most cases, resistance to Cry toxins in Lepidoptera fit with a single locus model (Ferré et al., 2008). However, the genetic characterization of three O. nubilalis

11 resistant strains revealed that laboratory-selected resistance to Cry1Ab had a polygenic 12 inheritance in this species (Crespo et al., 2009; Alves et al., 2006). Quantitative genetic 13 techniques have been applied to study insecticide resistance in Lepidoptera (Alinia et 14 al., 2000; Firko and Hayes, 1991; Tabashnik and Cushing, 1989) and they may be used 15 to study the genetic basis of resistance in $O$. nubilalis field populations. These 16 techniques provide estimates of genetic parameters whatever the number of genes 17 involved since they only require an observed or assumed continuous distribution of phenotypes (Firko and Hayes, 1990; Tabashnik and Cushing, 1989). Natural variation in resistance phenotype can be parted in environmental and genetic components, and the overall heritable genetic variation can be quantified.

The mode of action of the Cry1A proteins is very complex but the binding to a 22 receptor located in the larval midgut (as cadherin, cdh) is a key step (Vachon et al., 23 2012). High levels of resistance can be achieved by the alteration of the receptor 24 binding (Ferré et al., 2008) and in three lepidopteran species mutations in the $c d h$ gene 25 have been genetically linked with the resistance trait (Gahan et al., 2001; Morin et al., 
1 2003; Xu et al., 2005). Contribution of $c d h$ gene to the Cry1Ab resistance in $O$.

2 nubilalis may be assessed by using molecular markers, such as PCR-RFLP (Coates et

3 al., 2005) or exon-primed intron crossing (EPIC) PCR. This last technique detects intron

4 polymorphisms by using primers designed on the flanking exons (Lessa, 1992). The

5 EPIC-PCR markers are co-dominant, segregate according the Mendelian inheritance,

6 and have been developed and used for genetic surveys in organisms that lack sufficient

7 DNA sequence data (Arias et al., 2009; Bierne et al., 2000) or for gene mapping

8 (Wydner et al., 1994).

9 The objective of this study was to examine the variation in tolerance to Cry1Ab

10 in $O$. nubilalis through a quantitative genetic approach, by using a selection strategy

11 based on single-pair mating isolines derived from larvae collected in Spanish

12 commercial maize fields. Moreover, the association between $c d h$ gene and Cry1Ab

13 tolerance was assessed using an EPIC-PCR marker specifically developed for this

14 study.

\section{MATERIALS AND METHODS}

\section{$17 \quad 2.1$ Insect collection, rearing and bioassay}

The O. nubilalis populations used in the present study were obtained from diapausing last instar larvae collected in 2004 from two important Spanish maize growing areas, one (E) located in the Northeast (Ebro Valley) and another (B) in the Southwest (Badajoz), by dissecting damaged stalks from commercial maize fields. The larvae were moved to the laboratory to establish laboratory field-derived populations. The process used for the rearing is described in detail by Farinós et al. (2004).

For single-pair mating, each adult pair was confined in an oviposition cage consisting of a plastic cup (15.5 cm high x $6 \mathrm{~cm}$ diameter) with a fine mesh at its end, 
1 placed over and opposed to another plastic cup (7 cm high x $7 \mathrm{~cm}$ diameter). Cotton

2 soaked with a $10 \%$ honey solution was placed in the oviposition cages for feeding. The

3 top of each cage was covered with a black waxed paper sheet for the oviposition. After

$4 \quad 3$ and 7 days, egg masses were collected and transferred to plastic boxes containing

5 moistened filter paper until hatching. Cages for mating, oviposition and eggs incubation

6 were placed in a growth chamber (Sanyo MLR-350H, Sanyo, Japan) maintained at $25 \pm$

$7 \quad 0.5{ }^{\circ} \mathrm{C}, 70 \pm 5 \% \mathrm{RH}$, and with photoperiod of $16: 8 \mathrm{~h}(\mathrm{~L}: \mathrm{D})$.

8

Bioassays were performed with trypsin activated Cry1Ab toxin solubilized in

9 CAPS buffer ( $\mathrm{pH}$ 10.5), kindly provided by the laboratory DLR Rheinpfalz

10 (Neustadt/Weinstrasse, Germany). For testing larval tolerance, we decided to use a

11 threshold Cry1Ab concentration (40 ng/ $\mathrm{cm}^{2}$ ) which was expected to cause about $90 \%$ of

12 mortality according to our previous data (Farinós et al., 2004), to ensure the survival of

13 only the more tolerant individuals. We used the term tolerance in the sense defined by

14 Finney (1971), to refer to a quantitative measure of resistance that is normally

15 distributed among individuals within a population. The toxin dilution was applied on the

16 surface of artificial diet solidified in the wells of a 128-well plastic tray (Bio-Ba-128,

17 Color-Dec Italy, Capezzano Pianore, Italy). Trays were let dry in a laminar flow hood 18 and immediately five to seven neonate larvae were placed in each well and confined

19 with a cover (Bio-Cv-16, Color-Dec Italy, Capezzano Pianore, Italy). Trays were 20 incubated in the growth chamber at $25 \pm 0.3^{\circ} \mathrm{C}, 70 \pm 5 \% \mathrm{RH}$, and constant dark. Larval 21 mortality was recorded after 7 days. The larvae were considered dead if they did not 22 show any reaction when prodded. In this study, we refer to the larvae that survived to 23 the Cry1Ab screening as tolerant. Control mortality never exceeded 5\%.

242.2 Isoline establishment and screening for the Cry1Ab tolerance genetic basis 
A full siblings experimental design was used to investigate the genetic basis of

2 tolerance to Cry1Ab (Figure 1). We started with 110 crosses between two adults, each

3 one from one of the two different geographical locations ( $\mathrm{B} \times \mathrm{E}$ and reciprocal cross $\mathrm{E} \mathrm{x}$

4 B). The offspring $\left(F_{1}\right)$ of the pairs that oviposited more than 80 eggs was divided into

5 two parts within the isolines: the bioassayed and the control groups. The bioassayed

6 group consisted in about 125 neonates per isoline that were exposed to the Cry1Ab

7 protein. After seven days, mortality was recorded and tolerant larvae were moved to

8 non-supplemented artificial diet, where they were reared until the third instar. At this

9 point, tolerant larvae from isolines which showed a percentage of mortality higher than

$1060 \%$ were frozen while tolerant larvae from isolines with mortality less than $60 \%$

11 (called $\mathrm{I}_{\mathrm{T}}$ isolines) were reared until the adult stage. Neonate larvae of the control group

12 were reared on non-supplemented artificial diet until the third instar, and then frozen.

Tolerant adults from $\mathrm{I}_{\mathrm{T}}$ isolines were single-pair mated within each isoline

14 (forming the sib- $\mathrm{I}_{\mathrm{T}}$ subfamilies) to obtain the next generation $\left(\mathrm{F}_{2}\right)$. Again, the $\mathrm{F}_{2}$ progeny of each sib- $\mathrm{I}_{\mathrm{T}}$ subfamily was divided in two groups: the bioassayed and the

16 control groups. The bioassayed larvae were challenged with the same concentration of

17 Cry1Ab toxin used in the bioassays with the previous generation, following the procedure described before. Larvae from control group were reared until the third instar without Cry1Ab exposure and then frozen.

\subsection{Data analysis}

The estimate of the heritability of tolerance to Cry1Ab was determined

22 considering the mortality recorded after Cry1Ab exposure as a threshold character with

23 tolerance as underlying continuous variable (Falconer and Mackay, 1996) since our

24 methodology could not directly measure the tolerance level of each individual insect.

25 The heritability of tolerance to Cry1Ab was estimated by using two different methods: 
1 the first one based on variances among families in the unselected $F_{1}$ generation

2 (Tabashnik and Cushing, 1989; Bull et al., 1982) and the other one based on the actual

3 response to selection from one generation to the next (Firko and Hayes, 1990).

4

The first method, called the contingency method, was initially described by Bull and coworkers (1982) and later adapted by Tabashnik and Cushing (1989) to estimate heritability of insecticide resistance. As the proportion $(p)$ of the population expressing the tolerance trait (i.e., proportion of survivors) in the unselected generation $F_{1}$ was different from 0.5 , the $\rho_{x}$ value was determined from tables for computing bivariate normal probabilities (Owen, 1962), using the formula described by Bull et al. (1982). The heritability of tolerance was calculated as $2 \rho_{x}$ for full siblings. In this full siblings analysis, variation between families is often increased by the common environment and the dominance variance; thus our estimate of heritability only sets an upper limit (Falconer and Mackay, 1996).

In the second method, we used the proportion of tolerant individuals (in this case the survivors to the Cry1Ab treatment belonging to families with mortality lower than $60 \%$ ) in $F_{1}$ and $F_{2}$ generations, to calculate the regression coefficient of offspring on one parent $(b)$. In this model, the estimate of heritability of tolerance is obtained from the formula:

$$
h^{2}=2 b=2 \mu^{\prime} / \mu_{s}
$$

where $\mu_{\mathrm{s}}$ represents the mean of the underlying trait (tolerance) of the larvae that survived the treatment with the insecticidal toxin Cry1Ab and had offspring, and $\mu^{\prime}$ represents the mean of the tolerance in the $\mathrm{F}_{2}$ generation. Both values were obtained applying the method described by Hartl and Clark (1989) that uses the proportion of tolerant individuals scored in each generation. The interpretation of the correlation of tolerance between relatives in terms of heritability is subject to uncertainties about 
1 resemblances due to the common environment (Falconer and Mackay, 1996), thus also

2 in this case the estimate of heritability represents the upper limit.

The minimum number of independently segregating genes with equal and

4 additive effects on the tolerance to Cry1Ab was calculated using the method proposed

5 by Lande (1981) to estimate the effective number of genetic factors $\left(n_{E}\right)$ influencing a

6 particular trait within a population. The estimate was obtained with the formula:

$$
n_{E}=\frac{\left[\sum_{i=1}^{n} \sigma_{i}^{2}\right]^{2}}{\sum_{i=1}^{n}\left(\sigma_{i}^{2}\right)^{2}}
$$

7

8 where $\sigma^{2}$ is the variance recorded in each generation and $n$ is the number of generations.

9 To find the sampling variance of the underlying trait (tolerance) which mean is the

10 normal deviate $x$ for the corresponding $p$ (proportion of the population expressing the 11 tolerance trait) we used the formula:

$$
\sigma_{x}^{2}=(1-p) / i^{2} A
$$

where $i$ is the mean deviation of tolerant individuals from the population mean

14 (tabulated by Falconer and Mackay, 1996) and A is the number of tolerant individuals.

To compare the mortality values among groups of isolines (total isolines and $\mathrm{I}_{\mathrm{T}}$

16 isolines) and generations we used the non-parametric Mann-Whitney test implemented

17 in the GraphPad Prism 5 software (GraphPad software, La Jolla, CA, USA). The same

18 test was used to detect differences in mortality in $F_{1}$ generation among isolines

19 depending from the origin of the founders. We used ANOVA to determine if the arcsine transformed mortality frequencies were significantly different among sib- $\mathrm{I}_{\mathrm{T}}$ subfamilies

21 depending from the $\mathrm{I}_{\mathrm{T}}$ isoline of origin.

In the association studies between $c d h$ alleles and tolerance we compared the

23 allelic frequencies between tolerant and control groups within each $\mathrm{I}_{\mathrm{T}}$ isoline by the $\chi^{2}$ test. 


\subsection{DNA extraction, PCR reactions and cloning}

2

Total genomic DNA was extracted from the thorax of frozen parental adults or

3 from frozen whole larvae, using the PrepMan ${ }^{\mathrm{TM}}$ Ultra reagent (Applied Biosystems,

4 Foster City, CA, USA) following the manufacturer's instructions. DNA quality was

5 checked by agarose gel 1\% staining with ethidium bromide.

The EPIC marker used to study $c d h$ allele segregation was selected for the maximum size variability, after comparing all the $c d h$ regions (data not shown). We

8 previously demonstrated that Bt related $c d h$ from $O$. nubilalis is a single copy nuclear

9 gene (Bel et al., 2011), suitable to be studied in inheritance analysis. Primers 3.14 L (5’-

CCTAGGCGAGGAGTCTAT - $\left.\quad 3^{\prime}\right)$ and $3.14 \quad \mathrm{R} \quad$ (5’ -

11 CGAGCCGTACTTCGTCATGGAGAG - 3’) anneal on the exons 31 and 32 of the $c d h$

12 gene and the amplification results in a fragment containing only one intron. Both 13 primers were designed with Primer3 software (Whitehead Institute for Biomedical 14 Research, MA, USA) and purchased from GenScript Corporation (Piscataway, NJ, 15 USA). Amplification reactions were carried out by using $\leq 1 \mu \mathrm{g}$ of total DNA as 16 template, in a final volume of $25 \mu$ containing $0.4 \mathrm{U}$ of Expand High Fidelity Taq 17 polymerase (Roche Diagnostics, Mannheim, Germany), $0.2 \mathrm{mM}$ of each dNTP, $0.3 \mu \mathrm{M}$ 18 of each primer and the buffer provided with the Taq enzyme, using an Eppendorf

19 Thermal Cycler (Hamburg, Germany). The reaction conditions included an initial step 20 of denaturation at $94^{\circ} \mathrm{C}$ for 5 min, 35 cycles composed by denaturation at $94^{\circ} \mathrm{C}$ for 30 21 sec, primers annealing at $55^{\circ} \mathrm{C}$ for $30 \mathrm{sec}$ and elongation at $72^{\circ} \mathrm{C}$ for $2 \mathrm{~min}$, and a final 22 elongation step at $72^{\circ} \mathrm{C}$ for 5 min. Amplification products were separated in $1 \%$ agarose 23 gel and stained with ethidium bromide to detect size variations. Each amplified marker 24 was sequenced to confirm the identity. For this purpose, PCR amplicons were gel 25 purified using the GFX ${ }^{\mathrm{TM}}$ PCR DNA and Gel Band Purification Kit (GE Healthcare, 
1 Buckinghamshire, UK) following the manufacturer's instructions, and cloned in the

2 pGEM-t Easy Vector (Promega, Madison, WI, USA) with ligation $\mathrm{O} / \mathrm{N}$ at $4^{\circ} \mathrm{C}$. The

3 resulting constructs were cloned in competent Escherichia coli cells DB3.1 and the

4 positive colonies were screened by colony PCR. The plasmids were purified with the

5 High Pure Plasmid Purification Kit (Roche Diagnostics) and sequenced at the IBMCP

6 sequencing facilities (Valencia, Spain) using M13 primers. Sequences were aligned and 7 analyzed with the SeqMan software (DNAStar, Madison, WI, USA). In the EPIC-PCR 8 markers variability analysis, only indels (insertion/deletion) were scored, while SNPs 9 identified were not used for allele characterization.

\section{RESULTS}

\section{$12 \quad 3.1$ Genetic basis of Cry1Ab tolerance}

One hundred and ten single-pair matings were established from field-derived $O$. nubilalis populations from two representative Spanish Bt maize areas. Fifty-three pairs laid eggs enough to establish an isoline and to test the offspring, and the mean of the bioassayed larvae was 123 ( \pm 58 SD) per isoline (Table 1 ). The mortality caused by

Cry1Ab toxin in the $F_{1}$ generation varied extensively among families, ranging from 24 to $100 \%$ (Figure 2 ), with a mean mortality per isoline of $87 \%$ ( $\pm 17 \%$ SD) (Table 1$)$; nine isolines (17\% of the total) had no survivors after the treatment. The overall mortality observed was similar to the expected, based on our previous analyses of field Spanish populations (Farinós et al., 2004). As we used a high toxin dose causing about $90 \%$ of mortality, the distribution of the mortality frequencies was significantly different from a normal distribution (Shapiro-Wilk test, $W=0.7301, \mathrm{P}<0.0001$ ). Sex bias in the mortality values due to the origin of the founders of the isolines was not evidenced, because the mean mortalities of the progenies derived from the reciprocal 
1 parental crosses did not significantly differ (B x E $=88 \pm 16 \%$ SD; E x B $=86 \pm 19 \%$

2 SD; Mann-Whitney test, $U=263$; $\mathrm{P}=0.1426$ ).

3

4

Mortality values recorded in $F_{1}$ generation varied continuously from 70 to $100 \%$, with the exception of five isolines (\#1, \#7, \#76, \#81 and \#109), the $9 \%$ of the total (Figure 2). These isolines, called $\mathrm{I}_{\mathrm{T}}$ isolines, exhibited a larval mortality rate after the treatment with Cry1Ab below 60\%. The mean mortality of the $\mathrm{I}_{\mathrm{T}}$ isolines was $44 \%$ ( $\pm 14 \%$ SD) significantly lower than the one of the whole $F_{1}$ generation $(87 \pm 17 \%)$ (Mann-Whitney test, $U=14.5, \mathrm{P}<0.01$ ) (Table 1 ). To test if tolerance exhibited by the $\mathrm{I}_{\mathrm{T}}$ isolines was a genetically determined trait, tolerant insects from $\mathrm{I}_{\mathrm{T}}$ isolines were single-pair mated within each isoline and the offspring (corresponding to $F_{2}$ generation) was challenged with the same Cry1Ab doses used in the previous assays. From $\mathrm{I}_{\mathrm{T}}$ isolines \#1 and \#7 was possible to make only three single-pair matings for each one and no viable offspring was obtained. The other three $\mathrm{I}_{\mathrm{T}}$ isolines (\#76, \#81 and \#109) allowed the establishment of 31 single-pair matings which laid enough eggs (314 \pm 81 ) for the bioassays (Table 1). Mortality per subfamily in $F_{2}$ generation ranged from 28 to $89 \%$ with a mean of $62 \%$ ( $\pm 17 \%$ SD) (Figure 2$)$ that means a significant reduction with respect to the overall mortality showed by the previous generation (87 $\pm 17 \%$ ) (MannWhitney test, $U=203, \mathrm{P}<0.01$ ) (Table 1 ). In addition, $100 \%$ of mortality in $\mathrm{F}_{2}$ subfamilies was never obtained, whereas in the $\mathrm{F}_{1}$ generation the $17 \%$ of the isolines had no survivors. The distribution of mortality frequencies in $F_{2}$ generation was essentially continuous and, differently from the $F_{1}$ generation, did not deviate from a normal distribution (Shapiro-Wilk test, $W=0.9712, \mathrm{P}=0.5526$ ). The overall results evidenced a shift of the tolerance level after only one generation that indicates a fast response to the selection pressure (Figure 2). Within the $F_{2}$ generation, ANOVA did not detect differences among mortality means depending on the isoline of origin of the sib- 
$1 \quad \mathrm{I}_{\mathrm{T}}$ subfamilies (Table 1$)(F=0.1901, \mathrm{P}=0.347)$, indicating a similar response of all

2 isolines to the Cry1Ab selection.

4 was estimated to be 0.90, using the method described by Bull et al. (1982) based on

5 variance among families. This value indicates that up the $90 \%$ of the phenotypic

6 variation in the population may be due to additive genetic variation. When the

7 heritability of tolerance was estimated using the method based in response to the

8 selection, the result was 0.82 . Also in this second case, the common environment where

9 insects were kept could inflate the estimate and 0.82 represents the upper limit for 10 heritability.

11 Analysis with the Lande's method indicated that tolerance was not controlled by

12 a single major gene. Lande’s formula based on population variances recorded along the

13 selection yielded an estimate of 2 for the minimum number of effective segregating

14 factors with equal effect on Cry1Ab tolerance.

\subsection{Segregation of the cadherin alleles in the $I_{T}$ isolines}

The $c d h$ EPIC-PCR amplifications performed on the DNA from ten parental 17 adults ( $\mathrm{I}_{\mathrm{T}}$ isolines founders) resulted in the identification of five alleles (called allele A 18 to E) that showed length polymorphism plus a non-amplified fragment (null allele, 19 allele N) (Table 2). The amplicon sizes of the alleles A to E ranged from 758 to 1444 20 bp, and sequenciation evidenced that size differences were based on indels in the 21 intronic region. Six out of ten individuals analyzed were heterozygous for the $c d h$ gene.

22 The level of heterozygosity obtained in the amplifications with our marker (0.6) did not 23 differ from the expected heterozygosity (0.8) based on the Hardy-Weinberg equilibrium, 24 as indicated by the P-value of the Fisher's exact test (0.626). Mendelian inheritance of $25 c d h$ alleles in the control progenies was observed in all the $\mathrm{I}_{\mathrm{T}}$ isolines analyzed (Table 
13 ) since the observed genotypes did not significantly deviated from expected ratios,

2 although we detected a non-amplifying EPIC-PCR marker. This fact suggested that its

3 sequence was unambiguous and associated to only one $c d h$ allele. This data set pointed

4 out that the EPIC-PCR marker selected in this work was appropriate for the inheritance

5 analysis of the $c d h$ gene.

6 The $\mathrm{I}_{\mathrm{T}}$ isoline \#7 was discarded from the analysis of $c d h$ segregation because

7 resulted not informative since all the individuals of the $F_{1}$ generation were heterozygous

8 for both the $\mathrm{N}$ and $\mathrm{C}$ alleles (Table 3 ). In three out of the other four $\mathrm{I}_{\mathrm{T}}$ isolines, the

9 genotype ratios observed in control group compared with tolerant individuals were not

10 statistically different, neither in $F_{1}$ nor in the $F_{2}$ generations, indicating no association

11 between their $c d h$ alleles and the tolerance trait (Table 3). However, the isoline \#1

12 showed statistically different genotype ratios between control and tolerant insects, suggesting association between tolerance and $c d h$ alleles present in this isoline (Table 3). This observation could not be confirmed by the analysis of $c d h$ segregation in $F_{2}$ generation, because single-pair matings of $F_{1}$ tolerant adults from isoline \#1 did not produce any viable offspring. It should be noted that the predominant genotype in the group of tolerant larvae from the isoline \#1 was CD. However, the alleles C and D were present in the genotypes of tolerant individuals from other $\mathrm{I}_{\mathrm{T}}$ isolines, for which no differences were observed in genotype ratios between control and tolerant larvae.

\section{DISCUSSION AND CONCLUSIONS}

Previous genetic analysis of three different laboratory-selected O. nubilalis resistant strains described the resistance to Cry1Ab as incompletely recessive and controlled by more than one locus (Crespo et al., 2009; Alves et al., 2006), in contrast to what happens in the majority of the resistant strains of other lepidopteran species selected 
1 with Cry toxins (Ferré et al., 2008). In addition, variations in susceptibility to Cry1Ab

2 have been reported in field populations of $O$. nubilalis (Saeglitz et al., 2006; Farinós et

3 al., 2004; Siegfried et al., 2001; Marçon et al., 1999). These two evidences suggested

4 that tolerance to Cry1Ab, present in varying degrees in O. nubilalis field populations,

5 may be studied from the genetic point of view of a quantitative trait. Our results are

6 consistent with the hypothesis that some of the variation in tolerance within O. nubilalis

7 populations has a polygenic inheritance, since we found significant heterogeneity in

8 mortality among isolines that could be reduced in the $F_{2}$ generation after selection. In

9 fact, the variation in tolerance determined by polygenic inheritance is normally

10 distributed within a population and essentially continuous (Tabashnik and Cushing,

11 1989), resulting in a wide range of responses as we have observed in the present study.

12 The estimates of the upper limit of heritability for tolerance to Cry1Ab made by 13 using two different methods were 0.90 and 0.82 . Both values indicate that high levels of

14 additive genetic variation in larval tolerance to Cry1Ab toxin were present in the $O$.

15 nubilalis Spanish field-derived populations under study. The full siblings approach used

16 in this study only provides an upper limit for heritability because the common

17 environment and the dominance variance could inflate the estimates (Falconer and

18 Mackay, 1996). However, Tabashnik and Cushing (1989) found that the overestimation

19 bias introduced by experiments with full siblings may be expected as $<10 \%$. Therefore,

20 the heritability of tolerance to Cry1Ab estimated in this study is can be considered high,

21 but comparable with the highest heritability estimates of insecticide resistance obtained

22 in other insect pests reviewed by Omer and coworkers (1993). In the case of the $B$.

23 thuringiensis toxins, a heritability of tolerance to Cry1Ab of 0.52 was found for a small

24 sample of Chilo suppressalis from Philippines (Alinia et al., 2000), and Tabashnik

25 (1994) reported that realized heritability of resistance to Bt products in seven different 
1 lepidopteran species ranged from 0.04 to 0.61 .. However, it should be noted that

2 realized heritability after the first generation of selection often underestimates the

3 heritability in the base population (Falconer and Mackay, 1996).. In O. nubilalis, the

4 estimates of the realized heritability for Dipel resistance in five different field-collected

5 colonies ranged from 0.16 to 0.46 in the first six generations but decreased to $0-0.08$

6 in the last part of the selection process, when authors supposed to have obtained a

7 homogeneous resistance (Huang et al., 1999).

8 Estimates of genetic parameters like heritability are specific to the conditions under

9 which they were made, which means that heritability is not only a property of a genetic

10 trait but also of the population, the environment and the experimental measurements

11 (Falconer and Mackay, 1996; Firko and Hayes, 1990). Therefore, predictions based on

12 heritability estimates should be made with caution (Alinia et al., 2000). If the

13 heritability of tolerance in $O$. nubilalis populations under field conditions is as high as

14 the one estimated in our study, then the long term use of Bt products for controlling this

15 pest (like Bt maize expressing Cry1Ab toxin) would be seriously threatened by the

16 resistance apparition. So far, the strategy widely used for delaying evolution of insect

17 resistance to Bt crops is based on the creation of refuges for the random mating between

18 susceptible and resistant insects and on the expression of high concentration of Cry

19 toxins that reduce the dominance of the resistance and result into a decrease of the

20 heritability sufficient to decrease the response to selection (Tabashnik et al., 2004). Up

21 to now, this strategy has been highly effective in delaying apparition of O. nubilalis

22 resistant individuals under field conditions as no resistance incidences have been

23 reported (Farinós et al., 2004; Siegfried et al., 2001) or no major resistance alleles have

24 been detected (Hellmich and Siegrfried, 2012; Engels et al., 2011). 
In the present study, the $9 \%$ of the isolines, challenged with a Cry1Ab dose that

2 caused an overall mean mortality of $87 \%$, showed a significant higher survival rate.

3 This means that the occurrence of the Cry1Ab tolerance trait is frequent in our Spanish

4 field-derived populations. Previously, some authors reported that partial resistance

5 alleles were common in field populations from France and USA (Bourguet et al., 2003;

6 Andow et al., 2000). Larvae carrying partial resistance alleles could not complete the

7 development on Bt maize expressing Cry1Ab, but they caused more injury to Bt plants

8 than totally susceptible larvae (Andow et al., 2000). The additive effect of these alleles

9 (together with the environment) could result into a continuous variation of the tolerance

10 phenotype similar to the one detected in our study. Under this point of view, the

11 common presence of partial resistance alleles in O. nubilalis populations might favor

12 the evolution of a polygenic resistance under laboratory selection conditions (as the one

13 emerged in this study or the ones described by Crespo et al., 2009 and Alves et al.,

14 2006). However, Bt maize expressing a high dose of Cry1Ab toxin may only lead to a

15 monogenic resistance caused by rare alleles, which has never been detected in $O$.

16 nubilalis species (Siegfried and Hellmich, 2012). In accordance with this, up to now no

17 resistant larvae of $O$. nubilalis strains selected with Cry1Ab were able to develop on

18 commercial Bt maize plants (Crespo et al., 2009; Siqueira et al., 2004). The common

19 occurrence of partial resistance alleles in natural populations should be considered, to

20 avoid false early resistance detection in case of small changes in susceptibility to

21 Cry1Ab toxin. Besides, it would be interesting to investigate if these partial tolerance

22 alleles could act as modifier loci in the action of a major resistance allele, influencing

23 the emergence of resistance (Andow et al., 2000).

24 Monogenic inheritance of tolerance is associated with a decrease of the standard

25 deviation of the mortality values along the selection process, because a single genotype 
1 would be quickly selected. In the case of several genes involved in the tolerance, the

2 standard deviation would remain constant, and the selection response would be weak.

3 Our results showed similar standard deviation values among isolines and generations,

4 suggesting a polygenic inheritance of the tolerance. However, the fast response obtained

5 to the selection (shown by a clear reduction in the mean mortality in just one

6 generation) pointed out to few genes involved. Analysis of the minimum number of

7 freely segregating factors by using the Lande's method estimated that tolerance to

8 Cry1Ab was influenced by at least two loci. Previous studies with laboratory Cry1Ab

9 resistant colonies of $O$. nubilalis estimated (with Lande's method and direct and indirect

10 tests based on mortality recorded in backcross progeny) that the number of genes

11 involved in resistance of the SKY colony was from 2.6 to 5 (Crespo et al., 2009), while

12 in the resistant colonies Europe-R and RSST-R was higher than 10 (Alves et al., 2006).

13 These results only provide indirect evidences for the additive contribution of a multiple

14 number of loci to the tolerance or resistance phenotype in the O. nubilalis laboratory

15 selected strains studied. Only linkage mapping could provide the direct evidence of a

16 polygenic inheritance of the Cry1Ab tolerance. Nevertheless, to the date no genes have

17 been genetically associated with resistance in $O$. nubilalis.

18 One of the candidate Cry resistance genes is $c d h$, which was genetically linked to

19 resistance in three lepidopteran species: Heliotis virescens, Pectinophora gossypiella

20 and Helicoverpa armigera (Gahan et al., 2001; Morin et al., 2003; Xu et al., 2005). Its

21 role in the toxicity process caused by Cry1Ab in $O$. nubilalis was demonstrated by an ex

22 vivo study which correlated the expression of the $O$. nubilalis $c d h$ in sf9 cells with the

23 increased susceptibility to Cry1Ab (Flannagan et al., 2005). However, several studies

24 with $O$. nubilalis resistant strains did not clarify the involvement of the $c d h$ in resistance

25 to Cry1Ab toxin (Bel et al., 2009; Khajuria et al., 2009; Coates et al., 2008). We 
1 investigated $c d h$ allele segregation in the isolines selected for the tolerance trait using an

2 EPIC-PCR marker specifically developed for this study. This marker showed a random

3 pattern of indels and followed the Hardy-Weinberg equilibrium. Only the presence of a

4 null allele could affect its usefulness; however we observed that it did not interfere with

5 the Mendelian segregation. We detected six size alleles whose differences were due to

6 intron indels, confirming the genetic variation for the cdh locus that was described in

7 previous reports (Bel et al., 2009; Coates et al., 2005). One out of the five tolerant $\mathrm{I}_{\mathrm{T}}$

8 isolines (isoline \#1) showed significant differences in the genotype ratios of tolerant

9 insects compared with controls, being $\mathrm{CD}$ the predominant genotype in tolerant

10 individuals. However, the alleles $\mathrm{C}$ and $\mathrm{D}$ were also present in other $\mathrm{I}_{\mathrm{T}}$ isolines that did

11 not exhibit such association, even though never combined together as CD genotype. It is

12 worth to note that the association between $c d h$ and tolerance could not be confirmed by

13 segregation analysis in the $F_{2}$ generation, because isoline \#1 did not produce viable $F_{2}$

14 progeny. Although these findings appear to reject the implication of the $\mathrm{C}$ and $\mathrm{D} c d h$

15 alleles in the tolerance, it cannot be completely discarded since their whole sequences

16 have not been determined.

17 In summary, the analysis of field-derived $O$. nubilalis populations collected in

18 Spanish maize fields has revealed the common occurrence of Cry1Ab tolerance trait,

19 which can be studied with quantitative genetic techniques. Analysis of the effective

20 number of genetic factors indicated that few loci (at least two) contribute to the

21 tolerance phenotype and that $c d h$ could be one of them; further studies should be

22 performed to confirm this implication and to identify other loci involved in tolerance.

23 The results obtained in the present work have a special relevance from the resistance

24 management point of view. The monitoring of field evolved resistance should be aware

25 about the relevance to track and deal with the $O$. nubilalis tolerance trait since it may 
confer to the insects the ability to survive on Bt plants during short periods of time, which would enhance the conditions for a potential development of resistance.

\section{AKNOWLEDGEMENTS}

Support for this project was provided by the EU Fifth Framework Project “ProBenBt” (ref. QLK3-CT-2002-01969), by the Spanish Ministerio de Educación y Ciencia (project ref. at the University of Valencia AGL2006-11914) and by the Spanish Ministerio de Ciencia e Innovación (project ref. at the Centro de Investigaciones Biológicas of Madrid AGL 2009-08813). Cristina Crava was funded by a V Segles grant from the University of Valencia (Ref. UV-BVS-07-2083). Special thanks to Juan Ferré and Patricia Hernández Martínez for their thoughtful suggestions.

\section{REFERENCES}

1. Alinia, F., Cohen, M.B., Gould, F., 2000. Heritability of tolerance to Cry1Ab toxin of Bacillus thuringiensis in Chilo suppressalis (Lepidoptera: Crambidae). J. Econ. Entomol. 93, 14-17.

2. Alves, A.P., Spencer, T.A., Tabashnik, B.E., Siegfried, B.D., 2006. Inheritance of resistance to the Cry1Ab Bacillus thuringiensis toxin in Ostrinia nubilalis (Lepidoptera: Crambidae). J. Econ. Entomol. 99, 494-501.

3. Andow, D.A., Olson, D.M., Hellmich, R.L., Alstad, D.N., Hutchison, W.D., 2000. Frequency of resistance to Bacillus thuringiensis toxin Cry1 Ab in an Iowa population of European corn borer (Lepidoptera: Crambidae). J. Econ. Entomol. 93, 26-30.

4. Arias, A., Freire, R., Mendez, J., Insua, A., 2009. Intron characterization and their potential as molecular markers for population studies in the scallops Aequipecten opercularis and Mimachlamys varia. Hereditas 146, 46-57.

5. Bel, Y., Ferré, J., Escriche, B., 2011. Quantitative real-time PCR with SYBR Green detection to assess gene duplication in insects: study of gene dosage in Drosophila melanogaster (Diptera) and in Ostrinia nubilalis (Lepidoptera). BMC. Res. Notes 4, 84.

6. Bel, Y., Siqueira, H.A., Siegfried, B.D., Ferré, J., Escriche, B., 2009. Variability in the cadherin gene in an Ostrinia nubilalis strain selected for Cry1Ab resistance. Insect Biochem. Mol. Biol. 39, 218-223. 
7. Bierne, N., Lehnert, S.A., Bedier, E., Bonhomme, F., Moore, S.S., 2000. Screening for intron-length polymorphisms in penaeid shrimps using exon-primed introncrossing (EPIC)-PCR. Mol. Ecol. 9, 233-235.

8. Bourguet, D., Chaufaux, J., Seguin, M., Buisson, C., Hinton, J.L., Stodola, T.J., Porter, P., Cronholm, G., Buschman, L.L., Andow, D.A., 2003. Frequency of alleles conferring resistance to Bt maize in French and US corn belt populations of the European corn borer, Ostrinia nubilalis. Theor. Appl. Genet. 106, 1225-1233.

9. Bull, J.J., Vogt, R.C., Bulmer, M.G., 1982. Heritability of sex ratio in turtles with environmental sex determination. Evolution 36, 333-341.

10. Coates, B.S., Sumerford, D.V., Hellmich, R.L., Lewis, L.C., 2005. Sequence variation in the cadherin gene of Ostrinia nubilalis: a tool for field monitoring. Insect Biochem. Mol. Biol. 35, 129-139.

11. Coates, B.S., Sumerford, D.V., Lewis, L.C., 2008. Segregation of European corn borer, Ostrinia nubilalis, aminopeptidase 1, cadherin, and bre5-like alleles, from a colony resistant to Bacillus thuringiensis Cry1Ab toxins, are not associated with $\mathrm{F}_{2}$ weights when fed a diet containing Cry1Ab. Journal of Insect Science 8: 21.

12. Crespo, A.L., Spencer, T.A., Alves, A.P., Hellmich, R.L., Blankenship, E.E., Magalhaes, L.C., Siegfried, B.D., 2009. On-plant survival and inheritance of resistance to Cry1Ab toxin from Bacillus thuringiensis in a field-derived strain of European corn borer, Ostrinia nubilalis. Pest. Manag. Sci. 65, 1071-1081.

13. Dhurua, S., Gujar, G.T., 2011. Field-evolved resistance to Bt toxin Cry1Ac in the pink bollworm, Pectinophora gossypiella (Saunders) (Lepidoptera: Gelechiidae), from India. Pest. Manag. Sci. 67, 898-903.

14. Engels, H., Bourguet, D., Cagan, L., Manachini, B., Schuphan, I., Stodola, T.J, Andow, D., 2010. Evaluating resistance to Bt toxin Cry1Ab by $F_{2}$ Screen in European populations of Ostrinia nubilalis (Lepidoptera: Crambidae). J. Econ. Entomol. 103, 1803-1809.

15. Falconer, D.S., Mackay, T.F.C., 1996. Introduction to quantitative genetics, fourth ed. Longman, New York.

16. Farinós, G.P., Andreadis, S.S., de la Poza, M., Mironidis, G.K., Ortego, F., Savopoulou-Soultani, M., Castañera, P., 2011. Comparative assessment of the fieldsusceptibility of Sesamia nonagrioides to the Cry1Ab toxin in areas with different adoption rates of Bt maize and in Bt-free areas. Crop Prot. 30, 902-906.

17. Farinós, G.P., de la Poza, M., Hernandez-Crespo, P., Ortego, F., Castañera, P., 2004. Resistance monitoring of field populations of the corn borers Sesamia nonagroides and Ostrinia nubilalis after 5 years of Bt maize cultivation in Spain. Entomol. Exp. Appl. 110, 23-30.

18. Ferré, J., Van Rie, J., Macintosh, S.C., 2008. Insecticidal Genetically Modified Crops and Insect Resistance Management (IRM). In: Romeis, J., Shelton, A.M., Kennedy, G.C. (Eds.), Integration of insect-resistant genetically modified crops within IPM programs. Springer Netherlands, pp $41-85$.

19. Finney, D.J., 1971. Probit analysis. Cambridge University Press, Cambridge, UK.

20. Firko, M.J., Hayes, J.L., 1990. Quantitative genetics tools for insecticide resistance risk assessment: estimating the heritability of resistance. J. Econ. Entomol. 83, 647654. 
21. Firko, M.J., Hayes, J.L., 1991. Quantitative genetics analysis of larval resistance to cypermethrin in tobacco budworm (Lepidoptera: Noctuidae). J. Econ. Entol. 81, 34 -40 .

22. Flannagan, R.D., Yu, C.G., Mathis, J.P., Meyer, T.E., Shi, X., Siqueira, H.A., Siegfried, B.D., 2005. Identification, cloning and expression of a Cry1Ab cadherin receptor from European corn borer, Ostrinia nubilalis (Hübner) (Lepidoptera: Crambidae). Insect Biochem. Mol. Biol. 35, 33-40.

23. Gahan, L.J., Gould, F., Heckel, D.G., 2001. Identification of a gene associated with Bt resistance in Heliotis virescens. Science 293, 857-860.

24. Hartl, D.L., Clark, A.G., 1989. Principles of population genetics, second ed. Sinauer Associates Inc, Sunderland, Massachusetts.

25. Huang, F., Higgins, R.A., Buschman, L.L., 1999. Heritability and stability of resistance to Bacillus thuringiensis in Ostrinia nubilalis (Lepidoptera; Pyralidae). Bull. Entomol. Res. 89, 449-454.

26. Khajuria, C., Zhu, Y.C., Chen, M.S., Buschman, L.L., Higgins, R.A., Yao, J., Crespo, A.L., Siegfried, B.D., Muthukrishnan, S., Zhu, K.Y., 2009. Expressed sequence tags from larval gut of the European corn borer (Ostrinia nubilalis): exploring candidate genes potentially involved in Bacillus thuringiensis toxicity and resistance. BMC. Genomics 10, 286.

27. Kruger, M., Van Rensburg, J.B.J., Van Der Berg, J., 2011. Resistance to Bt maize in Busseola fusca (Lepidoptera: Noctuidae) from Vaalharts, South Africa. Environ. Entomol. 40, 477-483.

28. Lande, R., 1981. The number of genes contributing to quantitative variation between and within populations. Genetics 99, 541-553.

29. Lessa, E.P., 1992. Rapid surveying of DNA sequence variation in natural populations. Mol. Biol. Evol. 9, 323-330.

30. Marçon, P.C., Young, L.J., Steffey, K.L., Siegfried, B.D., 1999. Baseline susceptibility of European corn borer (Lepidoptera; Crambidae) to Bacillus thuringiensis toxins. J. Econ. Entomol. 92, 279-285.

31. Ministerio de Agricultura, Pesca y Alimentación, 2012. http://www.magrama.gob.es/es/calidad-y-evaluacionambiental/temas/biotecnologia/organismos-modificados-geneticamente-omg/consejo-interministerial-de-ogms/superficie.aspx

32. Morin, S., Biggs, W.B., Sisterson, M.S., Shriver, L., Ellers-Kirk, C., Higginson, D., Holley, D., Gahan, L.J., Heckel, D.G., Carriere, Y., Dennehy, T.J., Brown, J.K., Tabashnik, B.E., 2003. Three cadherin alleles associated with resistance to Bacillus thuringiensis in pink bollworm. Proc. Natl. Acad. Sci. U. S. A 100, 5004-5009.

33. NASS - National Agricultural Statistics Service, 2012. Report Acreage. Agricultural Statistics Board, USDA.

34. Omer, A.D., Tabashnik, B.E., Johnson, M.W., Leigh, T.F., 1993. Realized heritability of resistance to dicrotophos in greenhouse whitefly. Entomol. Exp. Appl. 68, 211-217.

35. Owen, D.B., 1962. Handbook of statistical tables. Addison-Wesley Publishing Company, Reading, Massachussets. 
36. Saeglitz, C., Bartsch, D., Eber, S.,Gathmann, A., Priesnitz, K.U., Schuphan, I., 2006. Monitoring the Cry1Ab susceptibility of European corn borer in Germany. J. Econ. Entomol. 99, 1768-1773.

37. Siegfried, B.D., Zoerb, A.C., Spencer, T., 2001. Development of European corn borer on event 176 Bt corn: influence on survival and fitness. Entomol. Exp. Appl. $100,15-20$.

38. Siegfried, B.D., Hellmich, R.L, 2012 Understanding successful resistance management: the European corn borer and Bt corn in the United States. GM Crops Food. 3: $184-93$.

39. Siqueira, H.A., Moellenbeck, D., Spencer, T., Siegfried, B.D., 2004. Crossresistance of Cry1Ab-selected Ostrinia nubilalis (Lepidoptera: Crambidae) to Bacillus thuringiensis delta-endotoxins. J. Econ. Entomol. 97, 1049-1057.

40. Storer, N.P., Babcock, J.M., Schlenz, M., Meade, T., Thompson, G.D., Bing, J.W., Huckaba, R.M., 2010. Discovery and characterization of field resistance to Bt maize: Spodoptera frugiperda (Lepidoptera: Noctuidae) in Puerto Rico. J. Econ. Entomol. 103, 1031-1038.

41. Tabashnik, B.E., Cushing, N.L., 1989. Quantitative genetic analysis of insecticide resistance: variation in fenvalerate tolerance in a diamondback moth (Lepidoptera: Plutellidae) population. J. Econ. Entomol. 82, 5-10.

42. Tabashnik, B.E., 1994. Evolution of resistance to Bacillus thuringiensis. Annu. Rev. Entomol. 39, 47-79.

43. Tabashnik, B.E., Gould, F., Carriere, Y., 2004. Delaying evolution of insect resistance to transgenic crops by decreasing dominance and heritability. J. Evol. Biol. 17, 904-912.

44. Vachon, V., Laprade, R., Schwartz, J.L., 2012. Current models of the mode of action of Bacillus thuringiensis insecticidal crystal proteins: a critical review. J. Invertebr. Pathol. 111, 1-12.

45. Wydner, K.S., Sechler, J.L., Boyd, C.D., Passmore, H.C., 1994. Use of an intron polymorphism to localize the tropoelastin gene to mouse chromosome 5 in a region of linkage conservation with human chromosome 7. Genomics 23, 125-131.

46. Xu, X., Liangying, Y., Wu, Y., 2005. Distruption of a cadherin gene associated with resistance to Cry1Ac $\delta$-endotoxin of Bacillus thuringiensis in Helicoverpa armigera. Appl. Environ. Microbiol. 71, 948-954. 


\section{FIGURE CAPTIONS}

2 Figure 1. Diagram of the selection process.

3 Figure 2. Distribution of mortality per isoline, obtained in $F_{1}$ and $F_{2}$ generations. Mortality 4 was recorded after 7 days of Cry1Ab exposure. White bars indicate $F_{1}$ generation whereas 5 grey bars indicate $\mathrm{F}_{2}$ generation. Arrow heads indicate $\mathrm{I}_{\mathrm{T}}$ isolines (selected to found the $\mathrm{F}_{2}$ 6 generation because they had shown less than $60 \%$ of mortality in $\mathrm{F}_{1}$ generation).

7

8 


\section{TABLES}

Table 1. Larval survival of field-derived $O$. nubilalis isolines exposed to $40 \mathrm{ng}$ of Cry1 $\mathrm{Ab}$ per $\mathrm{cm}^{2}$ of artificial diet

\begin{tabular}{|c|c|c|c|c|c|c|}
\hline & \multicolumn{2}{|c|}{$F_{1}$ generation } & \multicolumn{4}{|c|}{$F_{2}$ generation } \\
\hline & $\begin{array}{l}\text { Overall } \\
\text { Isolines }\end{array}$ & $\mathrm{I}_{\mathrm{T}}$ isolines $^{\mathrm{a}}$ & $\begin{array}{c}\text { Overall Sib-I T } \\
\text { subfamilies }\end{array}$ & $\begin{array}{c}\text { Sib-IT } \\
\text { subfamilies \#76 }\end{array}$ & $\begin{array}{c}\text { Sib-I } \\
\text { subfamilies \#81 } \\
\end{array}$ & $\begin{array}{c}\text { Sib-IT } \\
\text { subfamilies \#109 } \\
\end{array}$ \\
\hline No. of single-pair matings & 110 & - & 52 & 15 & 20 & 11 \\
\hline No. of isolines screened & 53 & 5 & 31 & 11 & 15 & 5 \\
\hline $\begin{array}{l}\text { No. of eggs laid } \\
(\text { mean } \pm \text { SD })^{b}\end{array}$ & $\begin{array}{c}15242 \\
(288 \pm 78)\end{array}$ & $\begin{array}{c}1478 \\
(246 \pm 83)\end{array}$ & $\begin{array}{c}9743 \\
(314 \pm 81)\end{array}$ & $\begin{array}{c}4173 \\
(379 \pm 66)\end{array}$ & $\begin{array}{c}4390 \\
(293 \pm 65)\end{array}$ & $\begin{array}{c}1180 \\
(236 \pm 41)\end{array}$ \\
\hline $\begin{array}{l}\text { No. of Cry1Ab treated larvae } \\
(\text { mean } \pm \text { SD) }\end{array}$ & $\begin{array}{c}6506 \\
(123 \pm 58)\end{array}$ & $\begin{array}{c}760 \\
(152 \pm 42)\end{array}$ & $\begin{array}{c}3410 \\
(110 \pm 50)\end{array}$ & $\begin{array}{c}1443 \\
(131 \pm 51)\end{array}$ & $\begin{array}{c}1675 \\
(112 \pm 45)\end{array}$ & $\begin{array}{c}292 \\
(58 \pm 25)\end{array}$ \\
\hline $\begin{array}{l}\text { Mortality (\%) } \\
(\text { min-max) }\end{array}$ & $\begin{array}{l}87 \pm 17 \\
(24-100)\end{array}$ & $\begin{array}{l}44 \pm 14 \\
(24-56)\end{array}$ & $\begin{array}{l}62 \pm 17 \\
(28-89)\end{array}$ & $\begin{array}{l}60 \pm 16 \\
(29-87)\end{array}$ & $\begin{array}{l}66 \pm 17 \\
(28-89)\end{array}$ & $\begin{array}{l}55 \pm 16 \\
(35-73)\end{array}$ \\
\hline
\end{tabular}

\footnotetext{
${ }^{\mathrm{b}}$ mean \pm SD per isoline;

${ }^{\mathrm{c}}$ Data (mean \pm SD per isoline) recorded after 7 days of Cry1Ab exposure.
}

${ }^{\text {a }}$ Isolines that showed mortality lower than $60 \%$ in the $\mathrm{F}_{1}$ progeny, used to found the Sib-I $\mathrm{I}_{\mathrm{T}}$ subfamilies; 
Table 2. EPIC-PCR $c d h$ alleles detected in the founders of the $\mathrm{I}_{\mathrm{T}}$ isolines

\begin{tabular}{l|l|l|l}
\hline Allele name & GenBank acc. number & PCR product length & Intron length \\
\hline A & HQ185401 & $1444 \mathrm{bp}$ & $1287 \mathrm{bp}$ \\
B & HQ185402 & $1219 \mathrm{bp}$ & $1062 \mathrm{bp}$ \\
$\mathrm{C}$ & HQ185403 & $1024 \mathrm{bp}$ & $867 \mathrm{bp}$ \\
$\mathrm{D}$ & HQ185404 & $827 \mathrm{bp}$ & $670 \mathrm{bp}$ \\
E & HQ185405 & $758 \mathrm{bp}$ & $601 \mathrm{bp}$ \\
$\mathrm{N}$ & - & No amplifying & - \\
\hline
\end{tabular}


Table 3: $c d h$ genotypic ratios observed in the $\mathrm{F}_{1}$ and $\mathrm{F}_{2}$ generations of $O$. nubilalis $\mathrm{I}_{\mathrm{T}}$ isolines

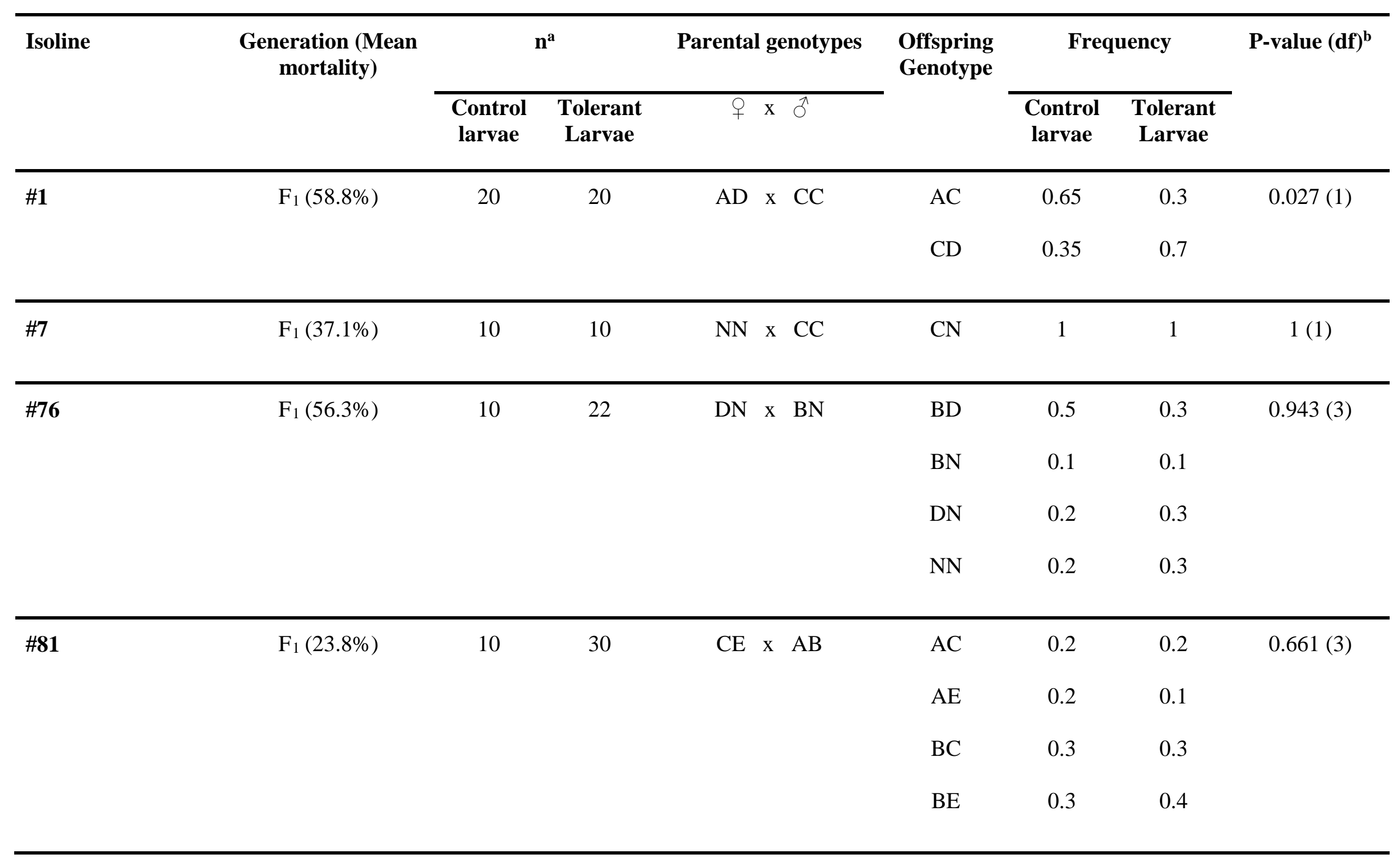




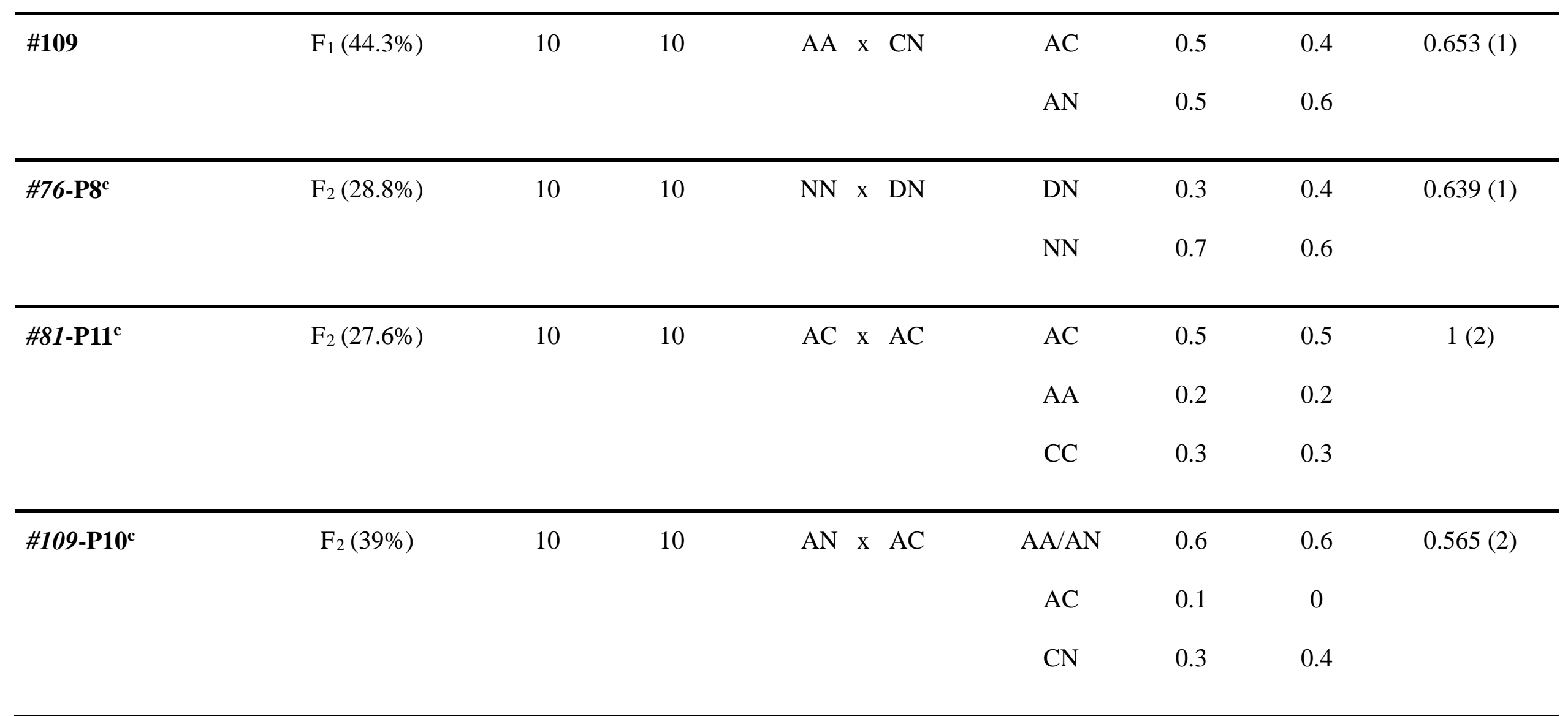

${ }^{\mathrm{a}}$ Number of individuals analyzed for $c d h$ segregation;

${ }^{\mathrm{b}} \mathrm{P}$-values obtained with $\chi^{2}$ test, comparing the genotype ratios recorded in the control and in the larvae tolerant to Cry1 $\mathrm{Ab}$;

${ }^{\mathrm{c}} \mathrm{SibI}_{\mathrm{T}}$-subfamilies showing the lowest mortality value within each isoline 
$\mathrm{P}$

$\mathrm{F}_{1}$

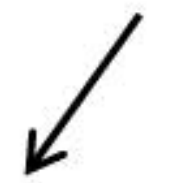

Untreated control

(reared to $3^{\text {rd }}$ instar and then frozen)

CrylAb screening

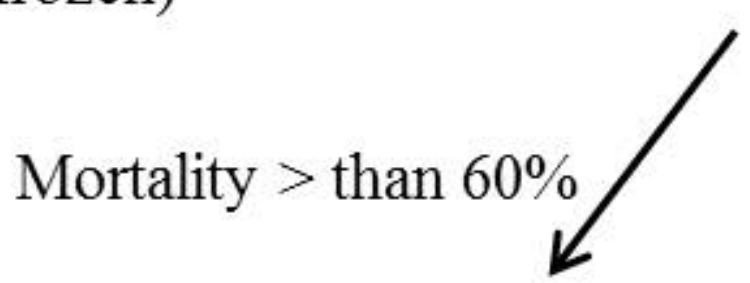

Larvae reared to $3^{\text {rd }}$ instar and

then frozen

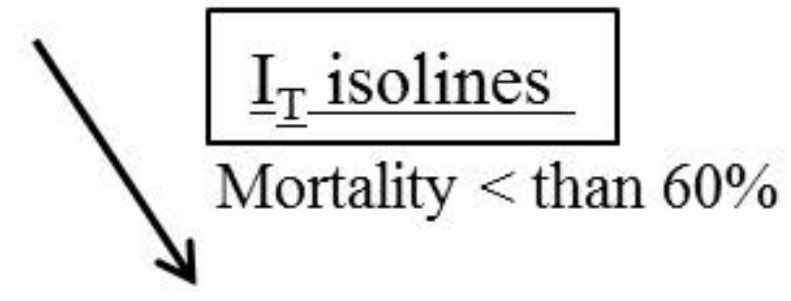

$1 \uparrow \times 1 \delta$

(Cry1Ab tolerant larvae)

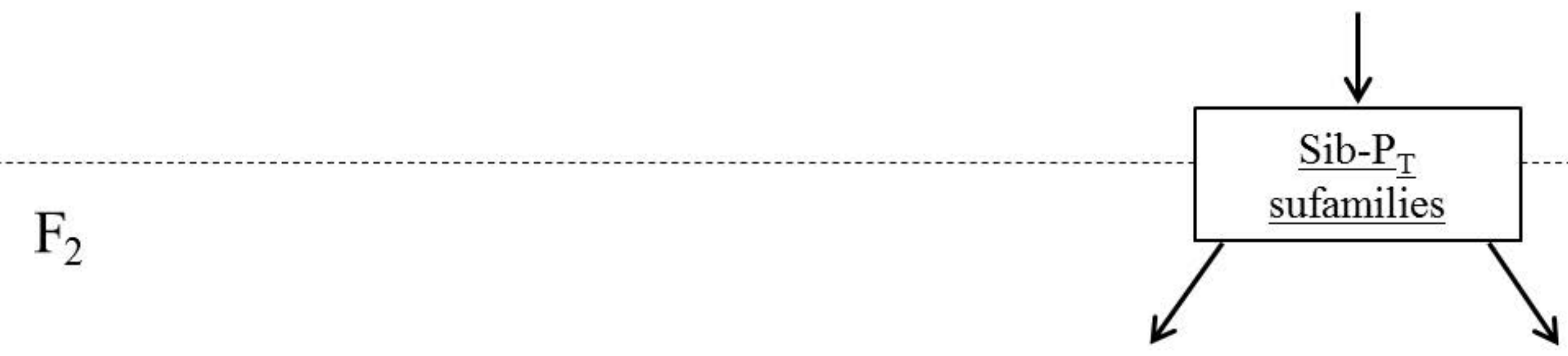

Untreated control

(reared to $3^{\text {rd }}$ instar and then frozen)

CrylAb screening

(reared to $3^{\text {rd }}$ instar and then frozen) 


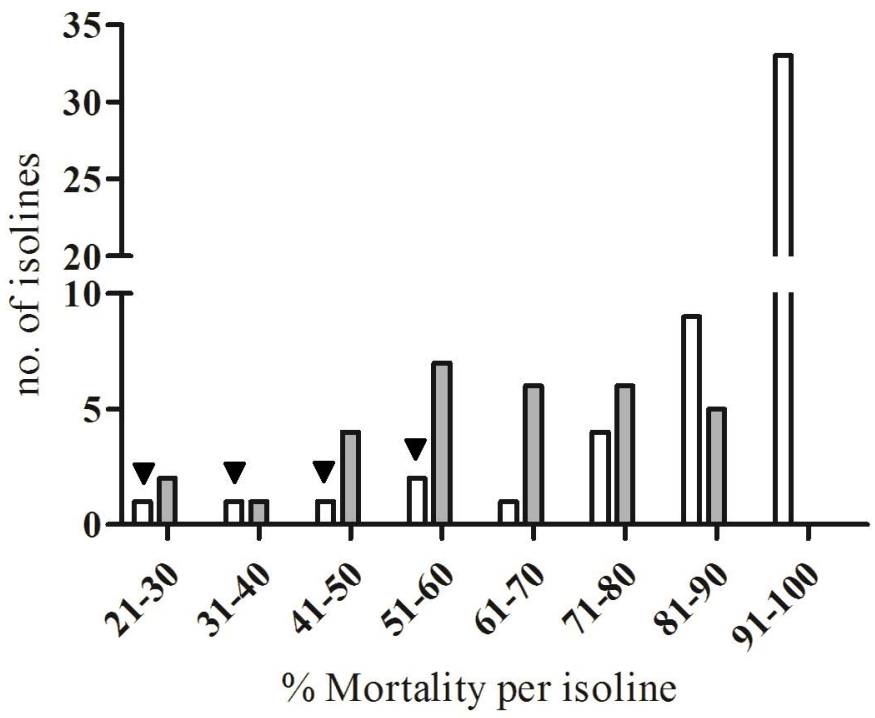

